\title{
BUDAYA TARI LENGGER DALAM PERSPEKTIF HUKUM ISLAM DI KABUPATEN WONOSOBO
}

\author{
Livia Setyawati \\ Fakultas Syariah, Institut Agama Islam Negeri Salatiga, Indonesia \\ Email: liviasetyawati10@gmail.com
}

\begin{abstract}
Received: 08-07-2020
Revised: 14-09-2020

Accepted: $12-10-2020$

\section{Lengger Dance Culture in Islamic Law Perspective in Wonosobo}

Abstract

Research on the culture of lengger dance in the perspective of Islamic law aims to find out how the implementation of the lengger dance is carried out by Muslims in Wonosobo Regency, to find out what factors cause the many fans of the lengger dance in Wonosobo Regency, to find out how the view of Islamic law affects the lengger dance as culture in Wonosobo Regency. This research uses a descriptive method. The data analysis technique used is qualitative analysis techniques. The results of the data from this article indicate that the lengger dance culture is carried out on certain occasions, such as welcoming the Indonesian Independence Day, weddings, circumcisions, dreadlocks etc. Lengger dance has developed until now, influenced by several historical, social and economic factors. Most of the dancers and the people of Wonosobo are Muslim, in the implementation of the lengger dance over time the meaning of philosophy in the lyrics or the Lengger dance is getting lost because what attracts dances with the beauty and courage of the dancer or just as entertainment. As the younger generation, they must preserve culture and stick to Islamic law, namely restoring the religious and moral meaning of the lengger dance and covering their genitals according to religious orders.
\end{abstract}

Keywords: Culture, Lengger Dance, Islamic Law, Wonosobo.

\section{Abstrak}

Penelitian budaya tari lengger dalam perspektif hukum islam bertujuan untuk mengetahui bagaimana pelaksanaan tarian lengger yang dilakukan oleh umat Islam di Kabupaten Wonosobo, untuk mengetahui faktor apa yang menyebabkan banyaknya penikmat tarian lengger di Kabupaten Wonosobo, untuk mengetahui bagaimanakah pandangan hukum islam mengena tarian lengger yang menjadi budaya di Kabupaten Wonosobo. Penelitian ini menggunakan metode deskriptif. Teknik analisis data yang digunakan yaitu teknik analisis kualitatif. Hasil data dari artikel ini menunjukkan bahwa budaya tari lengger dilaksanakan pada acara-acara tertentu, seperti penyambutan HUT Kemerdekaan Indonesia, pernikahan, khitanan, ruwatan rambut gimbal dll. Tari Lengger berkembang sampai saat ini dipengaruhi beberapa factor historis, sosial, dan ekonomi. Sebagian besar penari maupun masyarakat Wonosobo beragama Islam, dalam pelaksanaan tari lengger seiring zaman makna filosofs di dalam syair-syair ataupun tari Lengger semakin hilang karena yang menjadi hal yang menarik tarian dengan kemolekan dan kegagahan penari atau hanya sebagai hiburan. Sebagai generasi muda harus melestarikan budaya dan tetap berpegang teguh dengan syariat Islam yaitu mengembalikan makna religius dan moral tari lengger serta menutup aurat sesuai perintah agama.

Kata Kunci: Kebudayaan, Tari lengger, Hukum Islam, Wonosobo. 


\section{PENDAHULUAN}

Kebudayaan adalah suatu perkembangan dari majemuk budi-daya, artinya kekuatan dari akal. Konsep kebudayaan antara lain berarti keseluruhan gagasan dan karya manusia, yang harus dibiasakannya dengan belajar, beserta keseluruhan dari hasil budi dan karyanya itu,maka istilah "kebudayaan " dalam bahasa inggris berasal dari kata latin colere yang berarti "mengolah, mengerjakan ", terutama mengolah tanah atau bertani. Dari kata itu berkembang arti culture, sebagai segala daya dan usaha manusia untuk merubah alam. Kebudayaan adalah suatu kesatuan sistem nilai dan serangkuman pendirian dasar pembentuk seperangkat ide yang menjadi pegangan masyarakat dalam menentukan orientasi perilaku.

Indonesia sebagai negara yang mempunyai budaya dan kesenian yang heterogen, seperti seni music, seni tari, seni lukis, seni film dan lain sebagainya. Seni merupakan salah satu aspek yang perlu dipahami, tanpa adanya seni kehidupan manusia terasa gersang. Dalam menikmati kehidupan tentu kita membutuhkan suatu hiburan melalui seni. Terdapat beraneka ragam seni, salah satunya yaitu seni tari. Tari adalah gerak keseluruhan tubuh yang ditata dengan irama lagu pengiring, sesuai dengan lambang, watak, dan tema tari. Seni tari merupakan seni yang menggunakan dimensi tenaga, gerakan, waktu dan musik. Dari dimensi tersebut maka bisa dinikmati oleh para penikmat seni tari. Tarian berkembang sesuai dengan perkembangan zaman dan pola pikir masyarakat. Tari berkembang melalui dua jalur yaitu klasik dan rakyat. Tari klasik itu bersifat sederhana, serasi dan tidak berlebihan yang berasal dari istana. Tarian rakyat berasal dari luar istana yang dikembangkan oleh rakyat biasa. ${ }^{1}$ Ada beragam tari di Indonesia seperti tari Tungkat dari Sumatra Utara ${ }^{2}$, tari Serampang Dua Belas dari Sumatra Barat ${ }^{3}$, Tari Gantar dari Kalimantan ${ }^{4}$, Tari Katrili dari Sulawesi Utara ${ }^{5}$, Tari Jaipong dari Jawa Barat ${ }^{6}$. Setiap daerah baik kabupaten maupun provinsi memiliki tarian khas begitu juga dengan provinsi Jawa Tengah terdapat berbagai tari tradisional seperti Tari Bedhaya $^{7}$, Tari Gambyong ${ }^{8}$ dan juga Tari Lengger ${ }^{9}$.

${ }^{1}$ Dyah Sri Rahayu, "Kajian Bentuk Dan Fungsi Pertunjukan Kesenian Lengger Budi Lestari Kecamatan Kledung Kabupaten Temanggung," Skripsi 1 (2013): 1-126, Rahayu, Dyah Sri. 1 KAJIAN BENTUK DAN FUNGSI PERTUNJUKAN KESENIAN LENGGER BUDI LESTARI KECAMATAN KLEDUNG KABUPATEN TEMANGGUNG. Diss Universitas Negeri Semarang, 2013.

${ }^{2}$ Drs O K Zulfi et al., "MULTIETNIK KOTA MEDAN DALAM," no. September (2019).

3 Muhammad Zulaemy and Eggy Fajar Andalas, "Peradaban Melayu Kuno: Sejarah, Budaya, Dan Ekonomi Serdang Dalam Novel Penari Dari Serdang Karya Yudhistira ANM Massardi," Jurnal Satwika 4, no. 1 (2020): 71, https://doi.org/10.22219/satwika.vol4.no1.71-83.

4 Universitas Gadjah Mada Yogyakarta Eli Irawati1, Wisma Nugraha Ch.R2, dan Timbul Haryono3 Program Studi Pengkajian Seni Pertunjukan dan Seni Rupa, "KESINAMBUNGAN DAN PROSES TRANSMISI KELENTANGAN DALAM KONTEKS RITUAL MASYARAKAT DAYAK BENUAQ DI KALIMANTAN TIMUR," Journal of Food System Research 14, no. 2 (2007): 70-75, https://doi.org/10.5874/jfsr.14.2_70.

5 Material Offerings et al., "DOWRY AND MATERIAL OFFERINGS IN MARRIAGE TRADITIONS AMONG MUSLIM COMMUNITIES IN MANADO ( A SOCIAL CULTURAL STUDIES )" 43, no. 1 (2020): 119-38.

${ }^{6}$ Muhamad Caesar Jumantri and Trianti Nugraheni, "Pengkajian Gaya Busana Tari Jaipongan Karya Sang Maestro The Study of Jaipongan Dance Costume by The Maestro," Gondang 4, no. 1 (2020): 9-15.

7 P Komar, "DIMENSI ESTETIKA TARI BEDHAYA KETAWANG KERATON KASUNANAN SURAKARTA HADININGRAT,” 2019, 373426.

8 Yova Maerizal, “Tari Gambyong Bahasa Surakarta Ucapkan Selamat Datang," 2020, https://doi.org/10.31227/osf.io/7txbh.

${ }^{9}$ Umi Dwi Pemiluwati et al., "JURNAL SENI TARI Eksistensi Tari Lengger Laut Karya Otniel Tasman" 9, no. 1 (2020): 25-36. 
Kabupaten Wonosobo mempunyai berbagai macam kesenian tari salah satunya tari lengger yang merupakan tarian rakyat. Dalam kesenian mengacu kepada ekspresi dan hasrat yang terdapat di dalam manusia untuk dinikmati dengan telinga ataupun mata. Perwujudan manusia yang memiliki kebudayaan dan keindahan masyarakat Wonosobo diekspresikan melalui seni tari, musik, maupun seni rupa. ${ }^{10}$ Lengger, berasal dari kata eling ngger. Tarian ini memberikan nasihat dan pesan kepada setiap orang untuk dapat bersikap mengajak dan membela kebenaran dan menyingkirkan kejelekan. Tarian ini dirintis di Dusun Giyanti oleh tokoh kesenian dari Desa Kecis, Kecamatan Selomerto, Kabupaten Wonosobo, yaitu Bapa Gondowinangun antara tahun 1910. Selanjutnya antara tahun 60-an. Tarian ini dikembangkan oleh Ki Hadi Soewarno. Lengger merupakan tari tradisonal rakyat yang dipentaskan oleh dua orang, laki-laki dan perempuan, laki-laki memakai topeng dan perempuan mengenakan baju tradisional . mereka menari selama 10 menit dalam setiap babak. Diiringi alunan musik gambang, saron, kendang, gong dan lainnya. Tari lengger biasa dilakukan pada saat upacara ritual seperti bersih desa, ruwatan rambut gimbal, penyambutan tamu pernikahan, khitanan ataupun penyambutan hari raya idul fitri. Kata "lengger" berasal dari kata "Ileng" yang artinya ingat dan "ger" sebutan untuk anak kecil yang mempunyai arti kita harus selalu ingat kepada Allah SWT pencipta alam semesta yang patut untuk disembah dan dipuji. ${ }^{11}$ Sebagai kebudayaan lokal, tari lengger mempunyai keunikan karena di dalamnya terkandung nilai-nilai seperti estetika, perjuangan, kejujuran, dan juga kepercayaan. Kesenian tari lengger berorientasi pada acara ritual ataupun pemujaan. ${ }^{12}$

Agama Islam masuk ke Indonesia terutama wilayah Jawa dalam penyebarannya menggunakan kebudayaan yang sudah ada warisan dari agama Hindu dan Budha yang oleh para wali atau orang yang menyebarkan agama Islam dalam kebudayaan tersebut dimasuki nilai-nilai ajaran Islam. Melalui cara itulah agama Islam di tanah Jawa mudah diterima oleh masyarakatnya karena penyebarannya tidak dengan kekerasan akan tetapi melalui kebudayaan yang disukai oleh masyarakat Jawa. ${ }^{13}$ Banyak kebudayaan yang diakulturasikan oleh para wali begitupula tarian lengger yang diberi nilai-nilai keislaman di dalamnya. Tari lengger di kabupaten Wonosobo diawali dengan syair gending Babadono yaitu syair berisi permohonan rezeki, keselamatan, serta keberkahan hidup.

Seiring perkembangan zaman tari lengger semakin dinikmati oleh masyarakat tetapi nilai-nilai keislaman dan moral yang terkandung di dalam tari lengger semakin lama semakin pudar. Seni tari lengger saat ini hanya sebagai hiburan yang menawarkan gerak tubuh dan kecantikan semata sehingga menjadikan tari lengger hanya seperti mengeksploitasi erotisme ${ }^{14}$

${ }^{10}$ Inna Mutiara Putri, “Tari Kenya Lengger Karya Mulyani Kabupaten Wonosobo ( Kajian Koreografi )," 2015, 1-88.

${ }^{11}$ Fakultas Ilmu, "KEARIFAN LOKAL: NILAI DALAM MANDI KEMBANG LESON DI DESA GEMBLENGAN KABUPATEN WONOSOBO LOCAL WISDOM: THE VALUE OF KEMBANG LESON BATH TRADITION IN GEMBLENGAN VILLAGE, WONOSOBO REGENCY” 2, no. 1 (2020): $1-10$. $145-53$.

${ }^{12}$ Sugeng Iman Hartanto, "Perspektif Gender Pada Lengger Lanang Banyumas," Pantun 1, no. 212 (2016):

13Sains D A N Teknologi, “Universitas Islam Negeri Sultan Syarif Kasim Riau,” 2015, 2015..

${ }^{14}$ Hartanto, "Perspektif Gender Pada Lengger Lanang Banyumas.”. 
Masyarakat Wonosobo mayoritas beragama Islam dan penari lengger juga beragama Islam ${ }^{15}$, adanya salah satu kebudayaan tari lengger dalam pelaksanaannya ada hal-hal yang tidak sesuai atau bertentangan dengan apa yang diajarkan dan diperintahkan dalam agama Islam membuat saya tertarik untuk meneliti bagaimana kebudayaan tarian lengger ini dalam perspektif hukum Islam, karena sebagian besar penari lengger perempuan yang memperlihatkan aurat tubuhnya dan dinikmati oleh banyak orang baik laki-laki maupun perempuan, sedangkan di dalam agama Islam sendiri mengatur pemeluknya untuk mentaati perintah Allah SWT salah satunya menutup aurat dengan firman Allah di dalam Al-Qur'an, hadis Nabi Muhammad SAW, dan juga ijma para ulama atau kesepakatan ulama.

Dalam penelitian yang berjudul Fungsi Tari Lengger Punjen Dalam Upacara Nyadran Tenongan di Dusun Giyanti Desa Kadipaten Kecamatan Selomerto Kabupaten Wonosobo yang ditulis oleh Dhiajeng Rahma Yusantari menjelaskan tentang tari Lengger Punjen yang berfungsi sebagai legitimasi tatanan sosial, tari Lengger Punjen sebagai ajang berkumpul seluruh lapisan masyarakat di Dusun Giyanti dan sebagai pengakuan sehingga dalam upacara tersebut pejabat merasa diakui dan membutuhkan dukungan dari masyarakat sedangkan masyarakat merasa dilindungi oleh pejabat. Tari sebagai wahana ekspresi ritus yang bersifat sekuler dan religius, tari Lengger Punjen selalu ditarikan dalam Upacara Nyadran Tenongan sebagai sarana komunikasi dengan leluhur Dusun Giyanti. Walaupun ada pembahasan tentang fungsi tari lengger akan tetapi yang membedakan dengan penelitian saya yaitu juga membahas tentang perspektif hukum islam ${ }^{16}$.

Pada penelitian sebelumnya Kajian Bentuk dan Fungsi Pertunjukan Kesenian Lengger Budi Lestari Kecamatan Kledung Kabupaten Temanggung yang ditulis oleh Dyah Sri Rahayu menjelaskan tentang bentuk kesenian tradisional lengger Budi Lestari di desa Tuksari kecamatan Kledung kabupaten Temanggung dan fungsi kesenian lengger Budi Lestari di desa Tuksari kecamatan Kledung kabupaten Temanggung. Pembahasan tersebut yang membedakan pada penelitian saya yaitu perspektif hukum islam. Dalam penelitian sebelumnya yang berjudul Konstruksi Agama dan Masyarakat atas Tubub (Studi Kasus Penari Lengger Desa Gerduren Kecamatan Purwojati Kabupaten Banyumas) yang ditulis Oleh Robertus Suraji menjelaskan bagaimana para penari lengger yang berpakaian tidak sesuai norma yang ada di Indonesia melakukan pertunjukan yang disaksikan oleh berbagai kalangan dan dapat menimbulkan kemerosotan moral bagi geerasi muda ${ }^{17}$.

Penelitian Perspektif Gender pada Lengger Lanang Banyumas yang ditulis oleh Sugeng Iman Hartanto menjelaskan bagaimana peran perempuan dalam lengger lanang tersebut dikesampingkan karena kesenian tersebut khusus dimainkan oleh laki-laki ${ }^{18}$. Dalam penelitian Religiusitas Tari Lengger Desa Gerduren Kecamatan Purwojati Banyumas yang ditulis oleh Robertus Suraji menjelaskan bagaimana bahwa orang Islam yang melakukan tari lengger tetap mempercayai Allah tetapi mereka juga mempercayai roh halus yang berasal dari Allah. Berbeda

15 Wawancara Dengan Ilma Syalafiah (20 Tahun) Pelaku Penari Lengger Sanggar Swasti, Kalierang, Selomerto, Wonosobo, 2020.

16 Sri Rahayu, "Kajian Bentuk Dan Fungsi Pertunjukan Kesenian Lengger Budi Lestari Kecamatan Kledung Kabupaten Temanggung."

17.Suraji Robertus, "KONSTRUKSI AGAMA DAN MASYARAKAT ATAS TUBUH (Studi Kasus

Penari Lengger Desa Gerduren Kecamatan Purwojati Kabupaten Banyumas)" 66, no. 2 (2012): 37-39.

${ }^{18}$ Hartanto, "Perspektif Gender Pada Lengger Lanang Banyumas." 
dengan penelitian saya yang akan menjelaskan bagaimana para pelaku dan penonton tari lengger menurut perspektif hukum Islam. ${ }^{19}$

\section{METODE PENELITIAN}

Sesuai dengan permasalahan yang dikaji penelitian ini menggunakan metode kualitatif yang bersifat deskriptif. Penelitian kualitatif adalah penelitian yang berusaha mengungkap berbagai keunikan yang terdapat dalam individu, kelompok, masyarakat, atau organisasi dalam kehidupan sehari-hari secara menyeluruh, rinci, dalam, dan dapat dipertanggung jawabkan secara ilmiah (Ghony dan Fauzan 2012 : 32). Deskriptif adalah penelitian yang bertujuan menjelaskan sesuatu seperti apa adanya (as it is) secara mendalam (M. Junaidi Ghoni dan Fauzan Almanshur 2012 : 34). Data - data yang dikumpulkan berupa kata - kata, gambar, dan bukan angka.

Penelitian ini berjenis kualitatif dan menggunakan metode deskriptif, yang mana penelitian ini akan dilakukan dengan mencari informasi secara mendalam pada objek yang terbatas, yaitu budaya tari lengger di dalam perspektif hukum islam di Kabupaten Wonosobo. Kemudian penulisan laporan dengan menggunakan metode deskriptif, menggambarkan situasi dan kondisi yang nyata terjadi di lapangan. Pendekatan yang digunakan adalah Pendekatan normatif hukum, bertujuan untuk memperoleh fondasi dan tata cara mengenai pelaksanaan tari lengger menurut hukum Islam, pendekatan sosiologis, bermaksud untuk mengetahui kondisi sosial masyarakat Kabupaten Wonosobo, Lokasi yang dimaksud dalam penelitihan ini adalah Kabupaten Wonosobo. Lokasi ini ditentukan karena kesenian lengger berkedudukan di Kabupaten tersebut. Sumber dan data diperoleh dari berbagai literature yang memliki korelasi dengan masalah yang diteliti, baik berbentuk buku,maupun berbagai informasi melalui media masa.

Metode pengumpulan data adalah usaha untuk memperoleh data - data atau keterangan yang benar dan dapat dipertanggung jawabkan, untuk memperoleh data tentang masalah yang akan diungkap dalam penelitian ini. Metode pengumpulan data dalam penelitian ini adalah sebagai berikut; Menurut M. Djunaidi Ghony dan Fauzan Almanshur (2012: 165) metode observasi merupakan teknik pengumpulan data yang mengharuskan peneliti turun ke lapangan mengamati hal- hal yang berkaitan dengan ruang, tempat, pelaku, kegiatan, benda benda, wakyu, peristiwa, tujuan, dan perasaan. Metode observasi merupakan cara yang sangat baik untuk mengawasi perilaku subyek penelitian seperti perilaku dalam lingkungan atau ruang, waktu keadaan tertentu (Ida Bagus Mantra dalam Djunaidi). Teknik observasi adalah pengamatan tentang kondisi fisik lokasi penelitian, kondisi geografis desa, jumlah penduduk dan mata pencahariannya dan pencatatan terhadap apa yang penulis teliti. Alasannya menggunakan metode ini untuk memperoleh data murni ataudata yang sesungguhnya dengan menyusun terlebih dahulu hal- hal yang akan diamati, sehingga pengamatan akan lebih tersusun dan terarah. Penulis juga mengadakan pengamatan langsung terhadap kegiatan dalam pementasan kesenian tradisional lengger di Kabupaten Wonosobo. Observasi yang digunakan adalah observasi nonpartisipan, sebab pengamatan ini penulis tidak ikut aktif dalam kegiatan tersebut.

\footnotetext{
${ }^{19}$.Robertus Suraji, "Religiusitas Tari Lengger Banyumas” 1, no. 2 (2010): 123-39.
} 
Metode analisis data untuk mengambil kesimpulan tentang masalah yang akan diteliti. Data-data yang diperoleh dari hasil penelitihan harus dianalisis secara tepat agar kesimpulan yang di dapat tepat juga (M. Djunaidi dan Fauzan 2012 : 363). Metode ini sangat penting untuk menganalisis dari hasil penelitian yang diperoleh secara tepat agar kesimpulan yang di dapat tepat pula. Langkah-langkah analisis digunakan untuk memberi penjelasan secara keseluruhan tentang budaya lengger dalam perspektif hukum islam yang dijadikan pokok permasalahan dalam penelitian ini. Pengecekan keabsahan data yang dilakukan peneliti adalah dengan metode triangulasi. Secara sederhana triangulasi dapat dimaknai sebagai teknik pemeriksaan keabsahan data penelitian dengan cara membandingkan antara sumber, teori, maupun metode/teknik penelitian. Menganalisis data yang telah diperoleh kemudian disusun ke dalam sebuah laporan penelitian. ${ }^{20}$

\section{PEMBAHASAN}

\section{Pelaksanaan Budaya Tari Lengger di Kabupaten Wonosobo}

Wonosobo sebuah kabupaten yang masyarakatnya sebagian besar bermata pencaharian sebagai petani. Kebudayaan dan kesenian mengiringi pertumbuhan masyarakat Wonosobo, seperti kesenian tari lengger, ruwat cukur gimbal, nyadranan, dan lain sebagainya. Masyarakat Wonosobo sebagian besar beragama Islam. Agama Islam di Wonosobo tersebar dan berkembang di wilayah ini melalui dakwah yang dilakukan para ulama pada zaman dahulu.

Budaya Hindu tidak lepas dari adat kebiasaan masyarakat Wonosobo walaupun sudah memeluk Islam. Para ulama menyebarkan agama Islam di Wonosobo salah satunya menggunakan pendekatan budaya, budaya Hindu di masyarakat dimasuki atau diberi nilai-nilai agama Islam di dalamnya. Para ulama melakukan hal tersebut karena masyarakat yang sudah sangat erat hubungannya dengan budaya dan tradisi nenek moyang jika langsung dilarang maka agama Islam akan kesulitan dalam penyebarannya. Sebagai agama yang damai, penyebarannyapun para ulama tidak menggunakan kekerasan sehingga agama Islam mudah diterima oleh masyarakat. Budaya memperingati meninggalnya seseorang di dalam agama Hindu setelah meninggal seperti 3 hari, 7 hari, 40 hari dan 100 hari oleh ulama ratapan kesedihan diganti dengan bacaan tahlilan atau puji-pujian kepada Allah SWT dengan tujuan mendoakan orang yang sudah meninggal. ${ }^{21}$

Sesaji diganti dengan makanan dan di berikan kepada kerabat dan fakir miskin sebagai shadaqah dan masih banyak lainnya. Begitu juga tari lengger sebagai tari tradisional masyarakat Wonosobo yang dinikmati sampai saat ini, dibuktikan dengan adanya pertunjukan-pertunjukan dan pelestarian kebudayaan ini seperti di wilayah kecamatan Kejajar, Garung, Mojotengah, Kertek, Selomerto dan yang lainnya. Hampir setiap kecamatan terdapat sanggar atau komunitas penari lengger. Kebudayaan merupakan akar kata Budhayah diambil dari Bahasa sansekerta yang berarti akala tau budi ${ }^{22}$. Budaya yaitu hasil cipta karya manusia berupa seni, pengetahuan, kepercayaan, dam moral yang dilakukan secara turun temurun ${ }^{23}$. Kesenian

20 Sri Rahayu, "Kajian Bentuk Dan Fungsi Pertunjukan Kesenian Lengger Budi Lestari Kecamatan Kledung Kabupaten Temanggung."

${ }^{21}$ Universitas Islam and Negeri Sunan, Kontribusi Pemuda Dalam Digitalisasi Ilmu Falak Pada Aplikasi Islamicastro Dan Faza Haul, 2020.

22 Koentjaraningrat, Kebudayaan Mentalitas Dan Pembangunan (Jakarta: Gramedia, 1984).

${ }^{23}$ Rustiyanti Sri, Menyikap Seni Pertunjukan Etnik Di Indonesia (Bandung: STSI Press, 2010). 
adalah hasil karya manusia yang penuh kelembutan dan makna yang dalam tentang keindahan untuk dinikmati para penikmat seni. Orang yang menciptakan karya seni disebut sebagai seniman.

Kesenian berkembang di dalam masyarakat sesuai tempat dan waktu sehingga kesenian di daerah atau tempat tertentu berbeda dengan daerah lain sesuai dengan kondisi wilayah, struktur budaya dan ekonomi. Kesenian yang berkembang di rakyat jelata atau masyarakat umum disebut kesenian tradisional, dalam kesenian ini tidak begitu menekankan keindahan akan tetapi lebih menekankan maksud dan tujuan dari adanya kesenian seperti kesenian tari untuk meminta hujan di suatu tempat yang tandus. Kesenian tari lengger termasuk dalam seni tradisional kerakyatan karena seni tari ini berkembang di tengah-tengah masyarakat umum $^{24}$ yang harus dijaga kelestariannya ${ }^{25}$. Seni sebagai media untuk mengungkapkan ekspresi seseorang untuk dinikmati seniman dan juga orang lain. Seni tari merupakan ungkapan ekspresi dengan gerak ritmis dengan tubuh sebagai alatnya disertai irama atau music, tema, tata rias, tempat, waktu, suasana dan hal-hal lain sebagai pendukungnya.

Kesenian tari tidak dapat dipisahkan dengan iringan atau music karena keduanya sangat erat hubungannya. Dulu ketika jaman primitive masyarakat menggunakan teriakan, tangisan, dengungan sebagai iringan dalam tarian untuk mengungkapkan maksud yang terkandung dalam kesenian tari tersebut. Tema merpakan ide pokok, atau dasar dalam membuat seni, tema tidak lepas dari pengaruh Tuhan, alam dan manusia, dalam sebuah tema biasanya berhubungan dengan kehidupan. Pakaian atau kostum yang digunakan saat menari sebagai tanda atau ciri khas dalam tarian untuk memperindah walaupun begitu dalam pakaian penari juga harus memperhatikan tingkat kesopanan dalam berpakaian apakah sudah etis atau belum. Tata rias juga hal yang penting karena wajah biasanya menjadi pusat perhatian selain gerak tubuh. Tempat dan pengaturan cahaya atau lampu juga sebagai faktor pendukung yang penting $^{26}$.

Tari tradisional lengger tumbuh dan berkembang di kabupaten Wonosobo. Ada berbagai macam tari Topeng Lengger, seperti tari Topeng Angger Denok, tari Lengger Sontoloyo, dan tari lengger Punjen Bentuk sajian dari Lengger Wonosobo diawali tari Gambyong Lengger, Sulasih, Kinayakan, Bribil, Sontoloyo, Menyan Putih, Kebogiro, Rangurangu trance, Lengger Punjen, Cripingkuning, Jangkrik Genggong, Angger denok dan diakhiri Melik-melik ${ }^{27}$. Tari lengger merupakan sebuah tarian yang dilakukan oleh penari perempuan dan penari laki-laki. Ada berbagai gerak yang dilakukan dalam melakukan tari lengger seperti: 1) Ngencek berupa jalan kecil-kecil dengan cepat 2) Mincek-mincek berupa jalan yang lambat bergantian antara kaki kanan dan kiri dengan menyilang. 3) Ridong sampur, tangan kiri memegang ujung sampur sambil tangannya menekuk dan tangan kiri memegang ujung sampur yang satunya tangan tetap lurus dlanjutkan kepala menoleh ke kiri dan kanan. 4) Kebyak-

${ }^{24}$ Soedarsono, Jawa Dan Bali Dua Pusat Perkembangan Drama Tari Tradisional Indonesia (Yogyakarta: Gajah Mada University Press, 1972).

${ }^{25}$ Linsdsay Jenifer, Klasik Kitsh Kontemporer (Yogyakarta: Gajah Mada University Press, 1991).

26 Sri Rahayu, "Kajian Bentuk Dan Fungsi Pertunjukan Kesenian Lengger Budi Lestari Kecamatan Kledung Kabupaten Temanggung."

27 Dhiajeng Rahma Yusantari, "Fungsi Tari Lengger Punjen Dalam Upacara Nyadran Tenongan Di Dusun Giyanti Desa Kadipaten Kecamatan Selomerto Kabupaten Wonosobo,” Greget 16, no. 2 (2017): 104-15. 
kebyok sampur, kebyak tangan memegang setelah itu sampur disibakkan di pergelangan tangan, kebyok melepas sampur dari pergelangan tangan.

Tata rias penari wanita di rias wajahnya dengan cantik, menggunakan bedak dasar, bedak tabur, lipstick, blush on, aye shadow, pensil alis. Begitu juga penari laki-laki walaupun diberi make up di wajah akan tetapi tidak terlalu tebal. Penari lengger wanita menggunakan busana dan aksesoris sebagai berikut: 1) Jamang bulu, aksesoris di kepala seperti mahkota yang terbuat dari kulit dihiasi dengan bulu warna-warni dan juga hiasan mote untuk memperindah. Sumping, anting atau mote yang dipakai di telinga. 2) Baju rompi, pakaian atau kostum yang digunakan bermotif bunga-bunga sebagai simbol kecantikan wanita, terbuat dari beludru. 3) Stagen, kostum yang dipakai untuk mengencangkan perut menggunakan jarik/bawahan yang dililitkan di perut agar lekuk pinggang terlihat. 4) Jarik, kain bermotif bunga yang dipakai sebagai bawahan. 5) Sampur, kain Panjang yang diletakkan di leher penari atau selendang.

Penari lengger laki-laki menggunakan busana dan aksesoris : 1) Ikat kepala 2) Baju dengan motif bunga-bunga ataupun polos. 3) Celana cinde atau punjen, dengan motif payet di bawahnya dengan bahan beludru dan warna hitam. 4) Jarik yaitu kain bermotif biasanya bermotif batik, digunakan dengan cara antara ujung batik diletakkan di pusar dan dikencangkan dengan stagen . 5) Gelang 6) Keris 7) Stagen, digunakan untuk mengencangkan pinggang dan perut agar lekuk tubuh lebih terlihat. 8) Epek timang atau ikat pinggang. 9) Borosamir yaitu aksesoris yang digunakan di pinggang berbahan beludru dan bemotif payet digunakan di pinggang sebelah kanan satu dan sebelah kiri dua.

Property yang digunakan dalam tari lengger yaitu topeng, dengan ciri kumis tebal, giginya terlihat dan mempunyai karakter gagah. Lokasi atau tempat dalam pementasan tari lengger biasanya di tempat terbuka, akan tetapi ada juga yang di tempat tertutup di dalam Gedung atau ruangan. Alat music yang digunakan berupa gending atau gamelan. Dalam lengger punjen untuk mengawali tarian lengger dengan gending syair gondang keli yang menceritakan kisah kematian. Syairnya memberikan kisah bahwa ketika manusia meninggal dunia maka tidak ada hal apapun yang dibawa selain amal ibadah dan kebaikan di dunia.

\section{Syair Gondhang Keli}

Gondhang Keli semarangan

Wong mati mujur kalangan

Cucenono Cucenono banyu suci

Sandangan di ganti putih

Mertandake wes ramulih

Tumpakane kereta jawa

Roda papat rupa manungsa

Jujugane omah guwo

Tanpa bantal tanpa klasa

Sing ora ana lawange

Turu dewe ra ana kancane

Diurugi dianjang-anjang

Dikuri disawur kembang

Tangga-tangga pada nyawang

Karo nangis kaya wong nembang. 
Ketika meninggal dunia manusia hanya berpakaian dengan lembaran kain putih tanpa membedakan kedudukan dan pangkat di dunia semua sama baik orang miskin maupun orang kaya. Dibawa dengan keranda atau tempat meletakkan mayat terbuat dari kayu atau besi dibawa dengan diangkat di empat titik dan di iringi oleh manusia. Makna filosofis dari syair lengger begitu filosofis mengingatkan untuk selalu ingat kematian dan kebaikan-kebaikan dalam menjalani kehidupan di dunia ini. Masih banyak sekali syair ataupun gendhing yang mengiringi tari kesenian lengger. ${ }^{28}$

Nilai sebagai sebuah konsep, banyak dikenal dalam bidang ilmu filsafat yang berisi tentang bagaimana seseorang memandang sesuatu, baik terhadap barang maupun manusia. Nilai secara eksplisit merujuk pada hal-hal yang dilakukan manusia, apakah baik atau buruk, bagus dan jelek, tinggi dan rendahnya harga, dan lain sebagainya. Akan tetapi, nilai pada dasarnya dijadikan dalam memberikan nilai atau mutu terhadap sesuatu, seperti nilai keindahan, nilai kemanusiaan, nilai moral dan lain sebagainya, sebagaimana yang diungkapkan oleh Notonegoro dalam Budiyono bahwa nilai tidak hanya melekat pada sesuatu yang memiliki wujud saja, tetapi melekat pada sesuatu yang tidak berwujud (abstrak) yang hanya dapat dirasakan manusia, karena itu nilai dapat dibagi menjadi tiga nilai pokok, yaitu: 1) Nilai material, nilai yang berguna bagi jasmani manusia 2) Nilai vital, nilai yang berhubungan dengan aktivitas kehidupan manusia. 3) Nilai kerohanian, nilai yang berguna bagi ruh atau rohani manusia. Nilai kerohanian dibagi menjadi : Nilai kenyataan atau kebenaran, bersumber pada rasio atau akal manusia. Nilai keindahan, estetis atau keindahan menjadi sumber bagi nilai keindahan.Nilai religius, bersumber dari akal dan budi manusia dengan penghayatan kepada Tuhan. ${ }^{29}$

\section{Budaya Tari Lengger Dalam Perspektif Hukum Islam}

Agama Islam mengatur pemeluknya dengan sedemikian rupa, mengatur hubungan dengan Allah SWT berupa ibadah-ibadah yang dilakukan sebagai hubungan hamba dengan Tuhannya. Seperti shalat, puasa, haji dan lain sebagainya. Selain hubungan dengan Tuhan juga mengatur hubungan dengan sesama manusia seperti muamalah, faraid, shadaqah dan lain sebagainya. Sebagai agama yang menuntun pemeluknya agar tidak tersesat maupun salah dalam menjalani kehidupan, agama Islam secara detail juga mengatur cara berperilaku, bersikap, dan berpakaian. Masalah aurat diatur dalam Al-Qur'an yaitu AS. An-Nur (24): 31 dan Al-Ahzab (33): 59.dan juga hadis-hadis Rasulullah SAW.

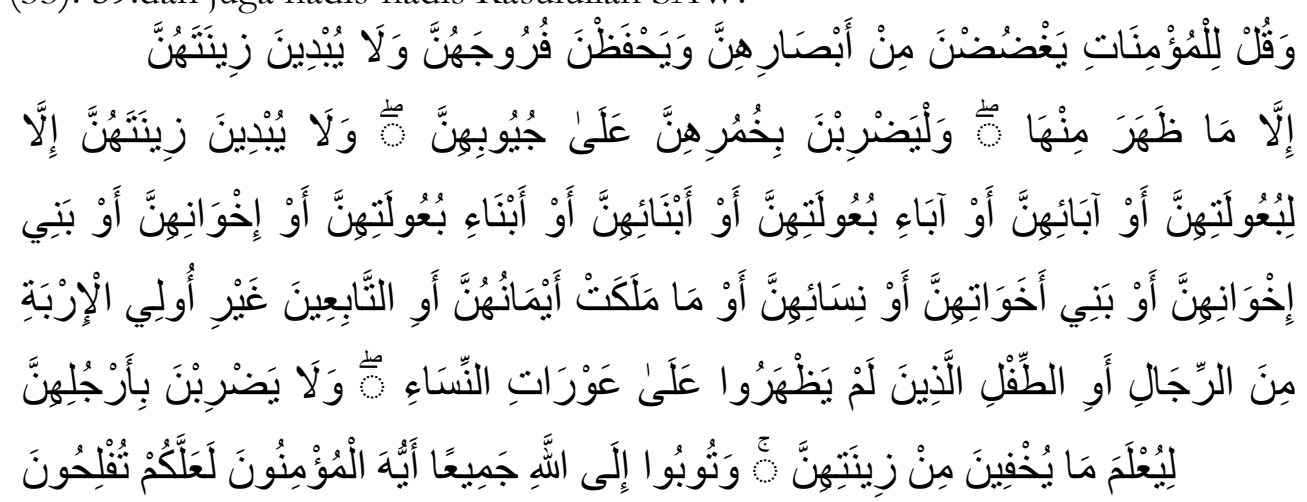

28 Yusantari.

${ }^{29}$ Hartanto, "Perspektif Gender Pada Lengger Lanang Banyumas.". 
Terjemahnya: Dan katakanlah kepada para perempuan yang beriman, agar mereka menjaga pandangannya, dan memelihara kemaluannya, dan janganlah menampakkan perbiasannya (auratnya), kecuali yang (biasa) terlihat. Dan bendaklab mereka menutupkan kain kerudung ke dadanya, dan janganlah menampakekan perbiasannya (auratnya), kecuali kepada suami mereka atau ayah mereka, atau ayah suami mereka, atau putra-putra mereka, atau putraputra suami mereka, atau saudara laki-laki mereka, atau putra saudara laki-laki mereka, atan putra-putra saudara perempuan mereka, atau para perempuan (sesame islam) mereka, atau bamba sahaya yang mereka miliki, atau para pelayan laki-laki (tua) yang tidak mempunyai keinginan (terbadap perempuan), atau anak-anak yang belum mengerti tentang aurat perempuan. Dan janganlah mereka mengentakean kakinya agar diketabui perbiasan yang mereka sembunyikan. Dan bertobatlah kamu semua kepada Allah, wahai orang-orang yang beriman, agar kamu beruntung. (QS. An-Nur: 31).

Dalam ayat tersebut dijelaskan bahwa Allah SWT memberikan perintah kepada hambanya para perempuan untuk menutup aurat kecuali terhadap orang-orang tertentu serta tidak memamerkan perhiasan yang dipakainya kepada orang lain, hal ini menunjukkan walaupun Allah SWT memberikan perintah menutup aurat akan tetapi tidak memberatkan karena ada pengecualian kepada orang-orang tertentu yang telah dibutkan diatas, dan mereka kebanyakan adalah anggota keluarga dan orang yang sering berada di rumah sehingga perempuan ketika di dalam rumah tidak memakai kerudung dan tidak ada orang lain yang haram melihatnya boleh saja, walaupun begitu hanya bagian-bagian tertentu saja yang boleh dilihat seperti rambut, kaki, dan tangan. QS Al-Ahzab (33): 59.

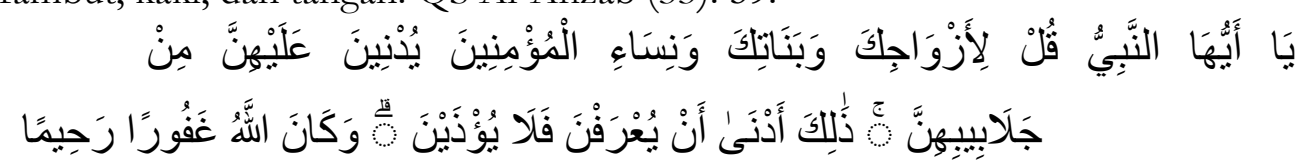

Terjemahnya: Hai nabi, Katakanlah kepada isteri-isterimu, anak-anak perempuanmu dan isteri-isteri orang mukmin: "Hendaklah mereka mengulurkan jilbabnya ke selurub tubub mereka". yang demikian itu supaya mereka lebih mudah untuk dikenal, Karena itu mereka tidak. di ganggu. dan Allah adalah Maba Pengampun lagi Maba Penyayang.

Adapun Hadis Nabi Muhammad SAW tentang perintah menutup aurat ketika Nabi menegur Asma binti Abu Bakar, ketika beliau datang ke rumah Nabi yang menggunakan busana agak tipis. Rasulullah memalingkan mukanya dan bersabda:

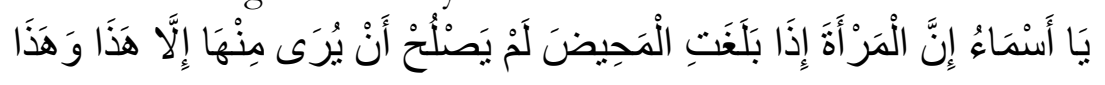

Artinya: Wabai Asma! Sesunggubnya wanita jikea sudah baligh maka tidak boleh nampak dari anggota badannya kecuali ini dan ini (beliau mengisyaratkan ke muka dan telapak tangan). (HR. Abu Daud, no. 4104 dan Al Baibaqi, no. 3218. Hadis ini di shabibkan oleb syaikh al-Albani rabimahullah). ${ }^{30}$

Dari kedua ayat Al-Qur'an dan hadis diatas kita bisa melihat bahwa Allah memberikan perintah langsung kepada umat Islam agar menutup aurat adapun aurat bagi perempuan seluruh tubuh kecuali telapak tangan dan wajah sedangkan aurat bagi laki-laki yaitu bagian pusar kebawah sampai lutut. Dari 4 mazhab yang banyak diikuti oleh sebagian besar umat muslim dunia, Imam Syafi'I, Imam Maliki, Imam Hanbali, dan Imam Hanafi juga sepakat bahwa menutup aurat hukumnya wajib dalam Islam. ${ }^{31}$ Fungsi atau manfaat bagi muslim baik

30 Antara Tafsir et al., "PAKAIAN MUSLIMAH DALAM AL-QURAN :,” 2008, 59-75.

${ }^{31}$ Muhammad Sudirman Sesse, “Aurat Wanita Dan Hukum Menutupnya Menurut Hukum Islam,” Jurnal Al-Maiyyah 9, no. 2 (2016): 315-31. 
perempuan atau laki-laki: 1) Menjalankan perintah Allah dan Rasulnya. 2) Menjaga diri dari fitnah. 3) Melindungi dari nafsu orang lain terhadap diri. 4) Mendapat ketenangan batin. 5) Sesuai dengan norma yang ada di masyarakat

Beragam kebudayaan dan kesenian yang sudah ada sejak zaman Hindu sampai sekarang dengan masyarakat Islam tetapi tetap mempertahankan kebudayaan di sisi lain juga melakukan ritual keagamaan atau melaksanakan perintah agama tentu menjadi polemik tersendiri.

\section{Faktor yang Mempengaruhi Perkembangan Budaya Lengger di Kabupaten Wonosobo}

Tari lengger berkembang seiring zaman, perkembangan tersebut dipengaruhi oleh beberapa faktor, diantaranya yaitu: Ekonomi, dalam masyarakat Wonosobo menjadi penari lengger merupakan keberkahan tersendiri, karena adanya pementasan maka akan mendapatkan imbalan uang, bukan sebagai mata pencaharian utama tetapi sampingan, karena tidak setiap hari acara tari Lengger digelar ${ }^{32}$. Masyarakat/lingkungan, kelestarian tari Lengger sampai saat ini juga dipengaruhi masyarakat yang mendukung dan anak muda yang menjadi generasi penerus yang terus ada, sehingga budaya tari Lengger tidak hilang ${ }^{33}$. Sosial, nilai-nilai pesan moral di dalam tari lengger menjadikannya tetap dijaga sampai saat ini ${ }^{34}$. Historis, sebagai tari tradisional sejak zaman Hindu, Budha sampai Islam masuk saat ini, di dalamnya terdapat nilainilai religius yang diakulturasi antara budaya Hindu dan Islam oleh para ulama.

Tari lengger mempunyai kelebihan diantaranya; Seni tari lengger sebagai hiburan ${ }^{35}$ Pariwisata $^{36}$, Menunjang ekonomi daerah, Menjadi budaya daerah, adapun kekurangan dari tari lengger yaitu; seiring perkembangan zaman nilai-nilai moral dan religus di dalamnya dilupakan dan seni tari Lengger ini hanya sebatas hiburan, Makna filosofis di dalam tari lengger yang seharusnya dihayati dijadikan pelajaran hidup semakin hilang, Seni tari lengger saat ini hanya sebagai hiburan yang menawarkan gerak tubuh dan kecantikan semata sehingga menjadikan tari lengger hanya seperti mengeksploitasi erotisme ${ }^{37}$

Perintah menutup aurat dalam Islam dengan kewajiban sebagai warga Indonesia untuk menjaga kearifan lokal dengan adanya kesenian tari lengger yang harus tetap dilestarikan sebagai warisan leluhur dan kebudayaan yang mengakar di masyarakat. Penari lengger wanita umumnya tidak memakai kerudung atau jilbab sebagai penutup kepala serta bagian tangan yang telanjang dengan kostum ketat menampilkan bagian yang menonjol dalam tubuhnya untuk dinikmati oleh para penikmat atau penonton baik laki-laki maupun perempuan, baik anak kecil maupun orang dewasa sampai kakek-kakek atau orang tua.

Terkadang dengan melihat tubuh indah para penari bisa saja menimbulkan nafsu atau keinginan terhadap sesuatu yang jika dilakukan bisa berakibat tidak baik ataupun kurang etis.

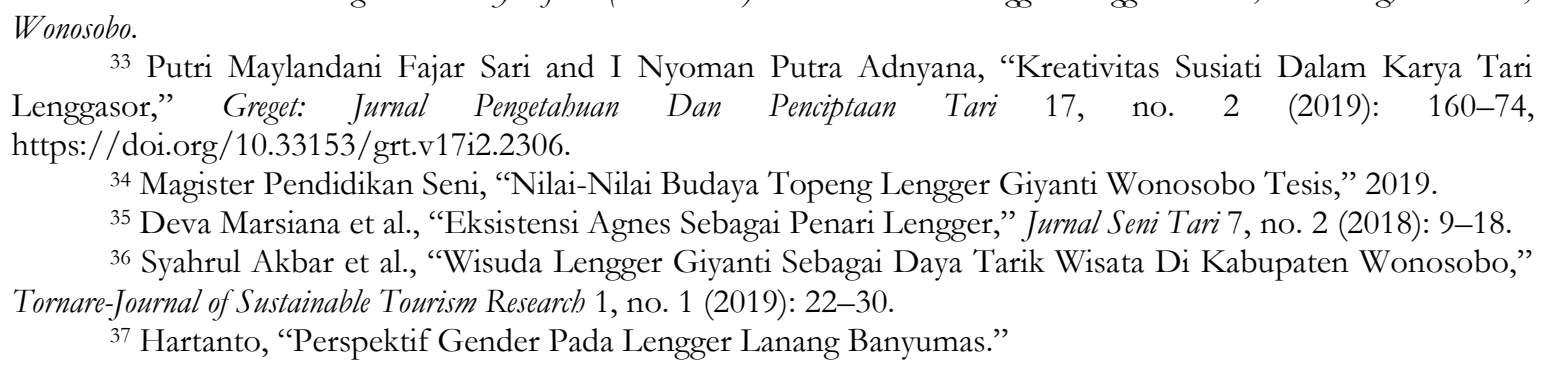


Tari lengger seiring perkembangan zaman mengalami kemunduran dalam hal nilai-nilai karena masyarakat saat ini hanya melihat sebagai hiburan semata. Nilai-nilai religius dan moral dalam syair-syair tari Lengger makna filosofisnya semakin terkikis seperti untuk berbuat kebaikan di dunia ini baik kepada sesama manusia ataupun dengan alam sekitar serta selalu ingat kepada sang pencipta alam semesta Allah SWT.

Untuk itu sebagai generasi muda tetap harus mempertahankan dan melestarikan budaya tari lengger, tetapi tidak melupakan makna religius dan moral yang terkandung di dalam tari lengger sebagaimana yang telah dibuat oleh para ulama maupun leluhur. Sebagai orang yang beragama Islam juga harus menerapkan syariat sesuai agama, memakai pakaian menutup aurat, karena yang lebih ditekankan bukan kemolekan bentuk tubuh tetapi makna filosofis budaya. Melestarikan kebudayaan di zaman globalisasi ini dimana batas wilayah dan negara sudah mulai kabur dengan kecanggihan teknologi saat ini. Pengikisan budaya juga sudah mula ada dimana anak muda saat ini lebih menyukai kebudayaan dari luar negeri dan mengidolakannya. Jika tidak ada anak muda yang mau mempelajari dan melestarikan budaya Indonesia maka semakin lama akan hilang. Keadaan seperti ini bisa dilakukan dengan menarik anak muda untuk menyukai dan melestarikan budaya akan tetapi juga tetap berada dalam tuntunan atau tetap mentaati perintah Allah SWT dengan pakaian menutup aurat atau baju Muslimah. Baju muslim saat ini sudah menjadi tren atau kesukaan anak muda hal ini bisa diaplikasikan di dalam tarian lengger sehingga budaya Indonesia bisa tetap dilestarikan dan agama Islam tetap bisa dijalankan sesuai perintahNya.

\section{KESIMPULAN}

Pelaksanaan tarian lengger di Kabupaten Wonosobo dilihat dari sejarah tari lengger ada sejak zaman Hindu dan Budha, agama Islam yang tersebar di tanah Jawa sampai ke wilayah Wonosobo merubah cara pandang dan hidup masyarakat yang memeluknya. Perubahan tersebut sampai ke bidang budaya seperti tari lengger, tari yang pada awalnya hanya bermuatan pemujaan kepada roh halus dan hiburan dirubah nilainya oleh ulama dengan nilai Islam. Syair-syair yang terkandung di dalamnya penuh dengan makna kehidupan dan religius. Pelaksanaan tari lengger dilakukan dalam acara-acara tertentu. Perlengkapan untuk alat music dengan gamelan, tata rias, tata panggung dan tata busana diatur sedemikian rupa untuk memperindah tarian lengger. Banyaknya penikmat tari lengger di Wonosobo seiring perkembangan zaman juga semakin mengikiskan nilai-nilai religius yang terkandung di dalamnya, tari lengger hanya berfungsi sebagai hiburan semata dengan menampilkan penari cantik dan baju terbuka. Dahulu property dan pakaian belum begitu diperhatikan, karena lebih menekankan keimanan agar menarik masyarakat. Seiring perkembangan zaman, agama Islam semakin tersebar luas dan dalam beragama sudah mencapai iman, Islam, ihsan, dan syariat, dimana pola kehidupan diatur sedemikian rupa hingga tata cara berpakaian baik laki-laki maupun perempuan.

Budaya tari lengger dilaksanakan pada acara-acara tertentu, seperti penyambutan HUT Kemerdekaan Indonesia, pernikahan, khitanan, ruwatan rambut gimbal dll. Tari Lengger berkembang sampai saat ini dipengaruhi beberapa factor historis, sosial, dan ekonomi. Sebagian besar penari maupun masyarakat Wonosobo beragama Islam, dalam pelaksanaan tari lengger seiring zaman makna filosofs di dalam syair-syair ataupun tari Lengger semakin hilang karena yang menjadi hal yang menarik tarian dengan kemolekan dan kegagahan penari atau 
hanya sebagai hiburan. Sebagai generasi muda harus melestarikan budaya dan tetap berpegang teguh dengan syariat Islam yaitu mengembalikan makna religius dan moral tari lengger serta menutup aurat sesuai perintah agama.

\section{REFERENSI}

Akbar, Syahrul, Evi Noviyanti, Ute Lies Siti Khadijah, and Awaludin Nugraha. "Wisuda Lengger Giyanti Sebagai Daya Tarik Wisata Di Kabupaten Wonosobo." Tornare-Journal of Sustainable Tourism Research 1, no. 1 (2019): 22-30.

Eli Irawati1, Wisma Nugraha Ch.R2, dan Timbul Haryono3 Program Studi Pengkajian Seni Pertunjukan dan Seni Rupa, Universitas Gadjah Mada Yogyakarta. "KESINAMBUNGAN DAN PROSES TRANSMISI KELENTANGAN DALAM KONTEKS RITUAL MASYARAKAT DAYAK BENUAQ DI KALIMANTAN TIMUR." Journal of Food System Research 14, no. 2 (2007): 70-75. https://doi.org/10.5874/jfsr.14.2_70.

Fajar Sari, Putri Maylandani, and I Nyoman Putra Adnyana. "Kreativitas Susiati Dalam Karya Tari Lenggasor." Greget: Jurnal Pengetahuan Dan Penciptaan Tari 17, no. 2 (2019): 160-74. https://doi.org/10.33153/grt.v17i2.2306.

Hartanto, Sugeng Iman. "Perspektif Gender Pada Lengger Lanang Banyumas." Pantun 1, no. 212 (2016): 145-53.

Ilmu, Fakultas. "KEARIFAN LOKAL: NILAI DALAM MANDI KEMBANG LESON DI DESA GEMBLENGAN KABUPATEN WONOSOBO LOCAL WISDOM: THE VALUE OF KEMBANG LESON BATH TRADITION IN GEMBLENGAN VILLAGE, WONOSOBO REGENCY” 2, no. 1 (2020): 1-10.

Islam, Universitas, and Negeri Sunan. Kontribusi Pemuda Dalam Digitalisasi Ilmu Falak Pada Aplikasi Islamicastro Dan Faza Haul, 2020.

Jenifer, Linsdsay. Klasik Kitsh Kontemporer. Yogyakarta: Gajah Mada University Press, 1991. Jumantri, Muhamad Caesar, and Trianti Nugraheni. "Pengkajian Gaya Busana Tari Jaipongan Karya Sang Maestro The Study of Jaipongan Dance Costume by The Maestro.” Gondang 4, no. 1 (2020): 9-15.

Koentjaraningrat. No Title Kebudayaan Mentalitas Dan Pembangunan. Jakarta: Gramedia, 1984.

Komar, P. "DIMENSI ESTETIKA TARI BEDHAYA KETAWANG KERATON KASUNANAN SURAKARTA HADININGRAT,” 2019, 373426.

Maerizal, Yova. "Tari Gambyong Bahasa Surakarta Ucapkan Selamat Datang," 2020. https://doi.org/10.31227/osf.io/7txbh.

Marsiana, Deva, Utami Arsih, Jurusan Pendidikan Sendratasik, and Universitas Negeri Semarang. "Eksistensi Agnes Sebagai Penari Lengger." Jurnal Seni Tari 7, no. 2 (2018): 918.

Offerings, Material, I N Marriage, Traditions Among, Muslim Communities, Tradisi Mahar, D A N Antar, Harta Pada, Perkawinan Masyarakat, and Muslim Di. "DOWRY AND MATERIAL OFFERINGS IN MARRIAGE TRADITIONS AMONG MUSLIM COMMUNITIES IN MANADO ( A SOCIAL CULTURAL STUDIES )" 43, no. 1 (2020): 119-38.

Pemiluwati, Umi Dwi, Moh Hasan Bisri, Jurusan Pendidikan Sendratasik, Fakultas Bahasa, and Universitas Negeri. "JURNAL SENI TARI Eksistensi Tari Lengger Laut Karya 
Otniel Tasman" 9, no. 1 (2020): 25-36.

Putri, Inna Mutiara. "Tari Kenya Lengger Karya Mulyani Kabupaten Wonosobo ( Kajian Koreografi )," 2015, 1-88.

Robertus, Suraji. "KONSTRUKSI AGAMA DAN MASYARAKAT ATAS TUBUH (Studi

Kasus Penari Lengger Desa Gerduren Kecamatan Purwojati Kabupaten Banyumas)" 66, no. 2 (2012): 37-39.

Rustiyanti Sri. Menyikap Seni Pertunjukan Etnik Di Indonesia. Bandung: STSI Press, 2010.

Seni, Magister Pendidikan. "Nilai-Nilai Budaya Topeng Lengger Giyanti Wonosobo Tesis," 2019.

Sesse, Muhammad Sudirman. "Aurat Wanita Dan Hukum Menutupnya Menurut Hukum Islam.” Jurnal Al-Maiyyah 9, no. 2 (2016): 315-31.

Soedarsono. Jawa Dan Bali Dua Pusat Perkembangan Drama Tari Tradisional Indonesia. Yogyakarta: Gajah Mada University Press, 1972.

Sri Rahayu, Dyah. "Kajian Bentuk Dan Fungsi Pertunjukan Kesenian Lengger Budi Lestari Kecamatan Kledung Kabupaten Temanggung." Skripsi 1 (2013): 1-126. Rahayu, Dyah Sri. 1 KAJIAN BENTUK DAN FUNGSI PERTUNJUKAN KESENIAN LENGGER BUDI LESTARI KECAMATAN KLEDUNG KABUPATEN TEMANGGUNG. Diss Universitas Negeri Semarang, 2013.

Suraji, Robertus. "Religiusitas Tari Lengger Banyumas" 1, no. 2 (2010): 123-39.

Tafsir, Antara, Hasbi Ash-shiddieqy Dan, Ahmad Nurrohim, Raudhatul Jannah, Muhammad Hasbi, and Quraish Shihab. "PAKAIAN MUSLIMAH DALAM AL-QURAN :," 2008, $59-75$.

Teknologi, Sains D A N. "Universitas Islam Negeri Sultan Syarif Kasim Riau,” 2015, 2015.

Wawancara Dengan Ilma Syalafiah (20 Tabun) Pelaku Penari Lengger Sanggar Swasti, Kalierang, Selomerto, Wonosobo, 2020.

Yusantari, Dhiajeng Rahma. "Fungsi Tari Lengger Punjen Dalam Upacara Nyadran Tenongan

Di Dusun Giyanti Desa Kadipaten Kecamatan Selomerto Kabupaten Wonosobo." Greget 16, no. 2 (2017): 104-15.

Zulaemy, Muhammad, and Eggy Fajar Andalas. "Peradaban Melayu Kuno: Sejarah, Budaya, Dan Ekonomi Serdang Dalam Novel Penari Dari Serdang Karya Yudhistira ANM Massardi." Jurnal Satwika 4, no. 1 (2020): 71. https://doi.org/10.22219/satwika.vol4.no1.71-83.

Zulfi, Drs O K, M Si, Drs O K Zulfi, and M Si. "MULTIETNIK KOTA MEDAN DALAM," no. September (2019). 